\title{
Are You Telling The Truth? Psychopathy Assessment and Impression Management in a Community Sample
}

\author{
James Freeman* and Freya Samson
}

Queensland University of Technology, School of Psychology and Counselling, Kelvin Grove Campus, 4059, Australia

\begin{abstract}
Objectives: Researchers have suggested that approximately $1 \%$ of individuals within the community have psychopathic tendencies (Neumann and Hare, 2008), although confirmatory evidence is scant. Design: The current study aimed to extend previous research beyond university student samples to explore the effect of impression management and self-deception on the identification of psychopathic traits. Methods: A non-incarcerated community sample comprising of 300 adults completed the Self-Reported Psychopathy scale - version 3 (SRP-III; Paulhus, Hemphill \& Hare, in press) as well as the Paulhus Deception Scales (PDS; Paulhus, 1998). Results: Results indicated that at least $1 \%$ of the current community sample had clear psychopathic tendencies, and that such tendencies were found in younger males who misused alcohol. Conclusions: Importantly, individuals with psychopathic traits did not present with an inflated propensity to distort assessment responses, which provides support for future research endeavours that aim to conduct larger-scale psychopathy assessments within the community. This paper further outlines the study implications in regards to the practical assessment of psychopathy.
\end{abstract}

Keywords: Psychopathy, impression management, assessment.

\section{INTRODUCTION}

The construct, measurement and effect of psychopathy have remained central issues within psychological research for over a century. However, while such research has traditionally focused on criminal offenders, increasing efforts are now being directed towards identifying and understanding psychopathic traits within the broader community. There are a number of benefits to this endeavour including the potential to extend current understanding of psychopathy which will not be confounded by criminality or the effects of longterm institutionalisation (Kirkman, 2002). More specifically, such pursuits provide an opportunity to disentangle the attributes that are specific to psychopathy and those specific to criminality, thus contributing to an overall understanding (as well as more effective measurement) of the psychopathy construct. Furthermore, given the link between psychopathy and violence (and particularly since psychopathy is one of the best predictors of violent recidivism), the importance of increasing scientific knowledge regarding the type and extent of psychopathy within the community becomes paramount (DeMatteo, Heilbrun \& Marczyk, 2005).

Despite this, there has been mixed preliminary success in identifying the extent and severity of psychopathic traits within the general community (Coid et al., 2009; Neumann and Hare, 2008). This is in part due to the fact that identifying the community integrated psychopath presently remains a considerable challenge. Firstly, defining psychopathy is a

*Address correspondence to this author at the Queensland University of Technology, School of Psychology and Counselling, Kelvin Grove Campus, 4059, Australia; Tel: +61 73138 4905; Fax: +61 73138 7532;

E-mail: je.freeman@qut.edu.au complex task and there has been considerable debate within the literature regarding the constructs that define psychopathy as well as appropriate methods to assess the various constructs. More specifically, this includes the relationship between affective and behavioural factors, the number of such constructs (Cooke \& Michie, 2001; Williams \& Paulhus, 2004 ), the role of antisociality in the psychopathy construct (Hare \& Neumann, 2010), the issue of psychopathy measured on a continuum versus discrete factors (Coid and Ulrich, 2010), how best to assess the different constructs (Livesley, Schroeder, Jackson and Jang, 1994), the overlap with other personality disorders, such as narcissistic, schizoid, histrionic and borderline personality disorders (Coid \& Ulrich, 2010) as well as how best to control for the distorting factors of impression management which may ultimately negate the accurate assessment of psychopathy via selfreport approaches (Lilienfeld, 1994). It is this latter issue which remains the focus of the current study, in addition to the need to extend psychopathy research beyond primarily student populations.

In regards to the issue of impression management, a primary reason for the dearth of research using self-report methods on non-incarcerated populations may (in part) be due to difficulties obtaining accurate data on both affective and behavioural factors. More specifically, because deceptiveness and manipulation are arguably key markers of psychopathy, the reliability of self-report methods aiming to identify psychopathy is questionable. Researchers have suggested that psychopaths are duplicitous (Mealey, 1995) and early research has shown that such manipulation is positively correlated with sexual deception (Seto et al., 1997) as well as an increased ability to "fake good" on psychological screening measures (Book et al., 2006). 
However, it is also noted that an opposing body of research has demonstrated that those with high psychopathic tendencies are no more effective at malingering (e.g., "faking good or bad") than the general population (Kropp \& Rogers, 1993). Furthermore, other researchers have found no link between psychopathy and malingering (Kucharski, Duncan, Egan \& Falkenbach, 2006). As such, it has been proposed that those with psychopathic traits may have insufficient insight to accurately describe themselves and there is also the suspected inability that self-report measures can correlate highly with either the PCL-R or other measures (Edens, Buffington, Tomicic, \& Riley, 2001). The extent of selfreport bias within the wider field of psychology is reflected in the development and incorporation of lie scales within a number of popular personality assessment scales (e.g., MMPI, PAI). The issue of socially desirable responding factors of self-deception and impression management identified by Paulhus (1984) are of particular relevance to the assessment of psychopathy.

Paulhus (1998) developed the Paulhus Deception Scales (PDS) specifically to address impression management (IM) and self-deceptive enhancement (SDE) in self-report methodologies. Therefore, incorporating the PDS into a selfreport study of psychopathy may shed light on the potentially confounding problem of dishonesty within self-report methods for this group, and it may be considered surprising that view such research endeavours have been completed within the arena of self-report psychopathy assessment.

A further methodological issue is that in regards to community-based samples, it is noteworthy that the study of psychopathy in non-incarcerated populations has focused heavily on student populations (Del Gaizo \& Falkenbach, 2008; DeMatteo et al., 2005; Forth et al., 1996; Mahmut et al., 2008; Salekin, Trobst \& Krioukova, 2001; Williams \& Paulhus, 2004). While meeting the non-incarcerated criteria, it is however questionable whether student samples are representative of the general community. Student populations may only be more representative of the general community (as opposed to criminal populations) to the extent that criminality has been removed. However, skewed variables such as age, gender and occupational distributions (e.g. young female psychology students) often result from student participant research (e.g. Mahmut et al., 2008). There is also a predictable lack of range in income, living arrangements and other socio-demographic factors amongst an exclusively student population. Furthermore, the base rate of psychopathy for student populations is expected to be low (Forth et al., 1996; Levenson, Kiehl, \& Fitzpatrick, 1995, Ross \& Rausch, 2001). In sum the populations most frequently studied in psychopathy research have been adult male criminal offenders and young female psychology students, neither of which are representative of the general community.

Despite the above, it has been estimated that psychopathy exists in $1 \%$ of the general non-incarcerated population (Kirkman, 2002; Neuman \& Hare, 2008). An early study, on a small sample sizes found a high prevalence of sociopathy in the general population, which is theorised to reflect behavioural (Factor 2) manifestations of psychopathy rather than affective or interpersonal differences (Factor 1) (Widom, 1977). In contrast, a more recent community-based study found that participants exhibited more core personality features of psychopathy (Factor 1) than core behavioural features (Factor 2) ( Dematteo et al., 2006). Other studies have found a base rate of Antisocial Personality Disorder (ASPD) much higher for males than for females in a general population studies (Robins, 1991), and psychopathy has been found to be associated with self-reported criminal activity, substance abuse and ASPD (Forth et al., 1996). Apart from these preliminary studies, research has yet to comprehensively examine the prevalence (and type) of psychopathic constructs that can be found among community samples.

Taken together, the current study aims to examine the existence and prevalence of psychopathic traits within a community sample, by obtaining data from a diverse sample in regards to age, educational backgrounds, income and employment status. Additionally, the study endeavours to examine the relationship between psychopathy and impression management, in particular, whether it is possible to identify psychopathic tendencies in high functioning individuals, given the tendency of the psychopath to be inclined to use deception.

\section{METHODOLOGY}

\section{Participants and Design}

A total of 300 adult community members participated in the study, mainly from the Brisbane metropolitan and surrounding area. All participants were required to be nonincarcerated adults over the age of 18 years. The voluntary and anonymous nature of the study was communicated via an information sheet distributed to all participants. Participation was without direct personal gain or benefit. Data was collected over a six month period (February - July 2010) and participants voluntarily completed either an on-line or paperbased version of the questionnaire. No between-group differences were found in responses between the data collection methods. There was no random assignment of participants to the sample group. Rather, a convenience sample was utilised where an e-mail (with a link to the questionnaire) was sent out to the authors' work colleagues. Participants were encouraged to forward the e-mail onto others, including family and friends. Additionally, the primary author placed copies of the questionnaire in various medical practices waiting rooms and patients completed the questionnaire while they waited for an appointment. The sampling approach resulted in a diverse range of general community members participating in the study.

\section{Demographic Details}

The first section of the questionnaire was designed to obtain a variety of demographic information such as age, gender, educational background, employment, income, living arrangements, marital status, etc. The demographic section also incorporated questions that related to: alcohol and drug use, traffic and parking offences, criminal conviction history, mental health, relationship and accommodation status and satisfaction levels.

\section{Psychopathy Scale}

The 64-item Self-Report Psychopathy scale - version III (SRP-III; Paulhus et al., in press) was utilised that measures 
a four-factor model of psychopathy: (a) interpersonal manipulation (b) callous affect (c) erratic lifestyle and (d) criminal tendencies (Paulhus, Hemphill, \& Hare, in press). The measure is designed to assess the core features of psychopathy among non-incarcerated populations and each item is rated on a 5-point Likert-scale from 1 (disagree strongly) to 5 (agree strongly). Twenty-one items across the four subscales are reverse scored and responses are summated for each subscale to deliver four scores. The total SRP-III score is also obtained by summing the four subscale scores. Paulhus et al., (in press) found the SRP-III to have good internal consistency (Cronbach's alpha $=.81$ ) and it has also more recently been used with incarcerated inmates (BaskinSommers et a., 2011).

\section{Deception Scales}

The Paulhus Deception Scales (PDS): The Balanced Inventory of Desirable Responding-7 (Paulhus, 1998) was used to measure deception. The PDS is a 40-item questionnaire that measures an individual's tendency to give socially desirable responses on self-report instruments. All items are presented as statements, for example, 'I sometimes tell lies if I have to' and 'I never swear'. The PDS contains two subscales, Self-Deceptive Enhancement (SDE) and Impression Management (IM) made up of 20 items each. SDE is the tendency to provide an agreeable self-profile that is due to an overly confident, yet inaccurate, self-image. In contrast, IM involves the tendency to consciously respond to items in an attempt to make the respondent appear favourable to whomever interprets the results. Each item is scored on a 5-point Likert-scale from 1 (not true) to 5 (very true). It is designed to be administered concurrently with other psychological assessment instruments. Items are phrased in contemporary, gender-neutral language. Paulhus (1998) found the PDS to have good internal consistency (Cronbach's $\alpha=.85$ ).

\section{RESULTS}

\section{Sample Characteristics}

Participants' ages ranged from 18 to 72 years of age $(M=$ $40.61, S D=12.12)$. As depicted in Table 1 , the majority of participants were employed $(85.75 \%)$, university educated $(64.7 \%)$, with the largest proportion being female $(70.3 \%)$,

Table 1. Demographic Characteristics of the Sample

\begin{tabular}{|c|c|c|c|c|c|}
\hline Variable & $\%$ & $n$ & Variable & $\%$ & $n$ \\
\hline Female & 70.3 & 211 & No & 14.3 & 43 \\
\hline Marital Status: & & & Salary: & & \\
\hline Married & 53.7 & 161 & $\$ 25001-\$ 50000$ & 23.3 & 70 \\
\hline De Facto & 16.0 & 48 & $\$ 50001-\$ 75000$ & 29.0 & 87 \\
\hline Divorced & 5.3 & 86 & $\$ 75001-\$ 100000$ & 12.7 & 38 \\
\hline Widowed & 1.7 & 5 & $\$ 100001-\$ 150000$ & 7.3 & \\
\hline Junior (Grade 10) & 6.0 & 18 & With parents & 6.0 & 18 \\
\hline Senior (Grade 12) & 10.7 & 32 & Rent alone & 9.3 & 28 \\
\hline TAFE/Tech College & 13.7 & 41 & Rent with Others & 16.0 & 48 \\
\hline University & 64.7 & 194 & Paying mortgage & 47.3 & 142 \\
\hline & & & Own home & 20.7 & 62 \\
\hline \multicolumn{2}{|l|}{ Alcohol Intake Frequency: } & & Mental Health Issues: & & \\
\hline Never & 9.0 & 27 & Yes & 29.0 & 87 \\
\hline
\end{tabular}

Note. Remaining $\%=$ missing data. 
Table 2. Cronbach's Alpha Coefficients for the SRP-III and PDS Scales

\begin{tabular}{|l|c|c|c|}
\hline \multicolumn{1}{|c|}{ Scale } & No. of Items & $\begin{array}{c}\text { Current Study: Cronbach's Alpha Coef- } \\
\text { ficients }(\boldsymbol{\alpha})\end{array}$ & $\begin{array}{c}\text { Original study: (Norm Sample): Cron- } \\
\text { bach's Alpha Coefficients }(\boldsymbol{\alpha})\end{array}$ \\
\hline \hline Overall SRP-III & 64 & .94 & .81 \\
\hline Interpersonal Manipulation (IPM) & 16 & .85 & .81 \\
\hline Callous Affect (CA) & 16 & .84 & .79 \\
\hline Erratic Lifestyle (ELS) & 16 & .85 & .74 \\
\hline Criminal Tendencies (CT) & 16 & .78 & .82 \\
\hline Overall PDS & 40 & .79 & .85 \\
\hline Impression Management (IM) & 20 & .75 & Not available \\
\hline Self-Deceptive Enhancement (SDE) & 20 & .79 & Not available \\
\hline
\end{tabular}

Note. SRP-III = Self-Report Psychopathy Scale - Version III; PDS = Paulhus Deception Scales.

Table 3. Norms, Self-reported Psychopathy (SRP-III) and Deception (PDS) Means and Standard Deviations According to Gender

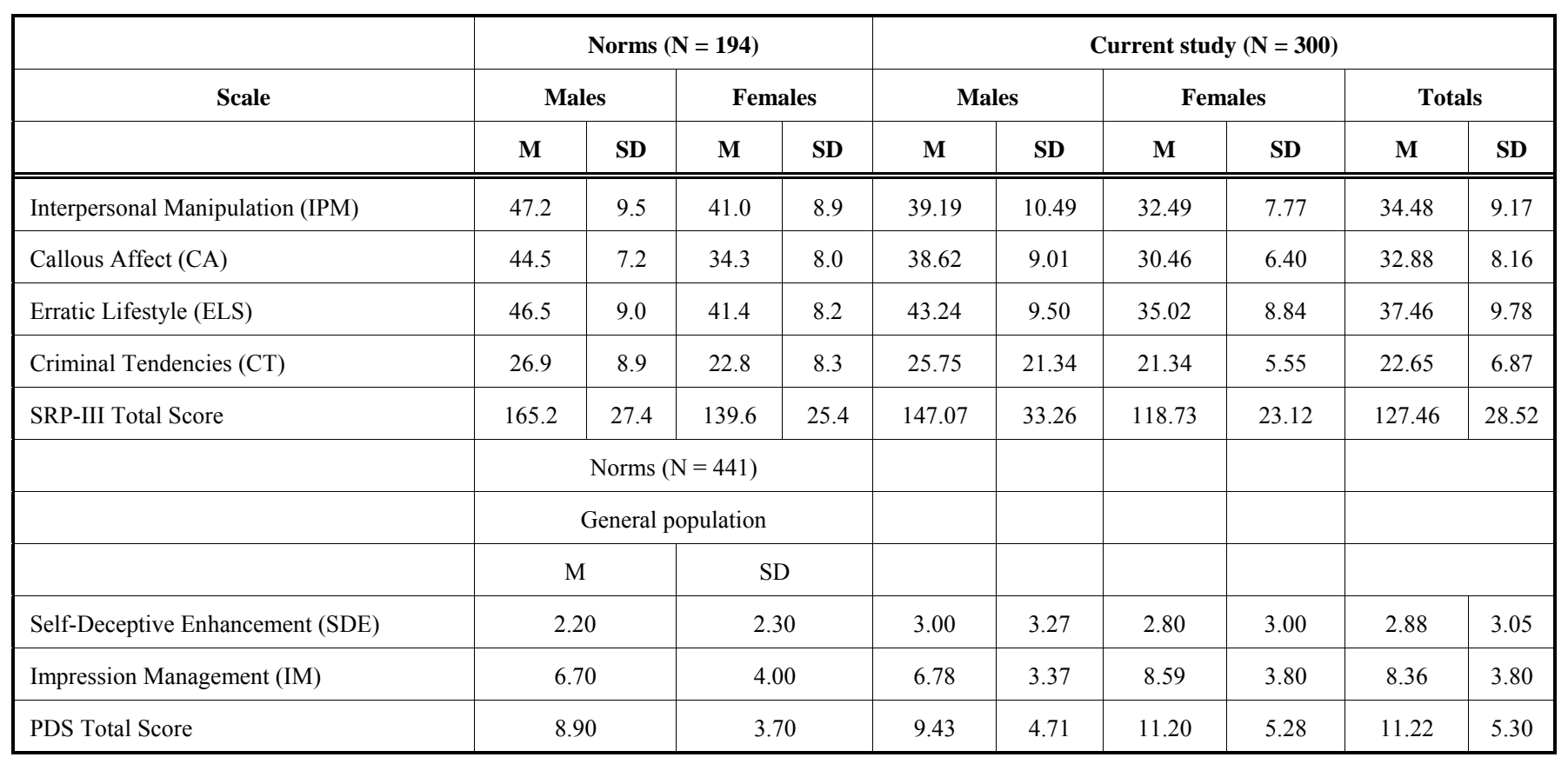

and over half were married $(53.7 \%)$ or in de facto relationships $(16 \%)$. The largest proportion $(29 \%)$ of participants earned between $\$ 50001$ - $\$ 75000$ per annum and just under half $(47.3 \%)$ had a mortgage. Nearly $30 \%$ of participants reported having had mental health issues in the past, which mainly involved depression and/or anxiety. In contrast, only $4.3 \%$ of participants admitted to having had a criminal conviction.

\section{Factor Analysis}

The 64-item SRP-III and the 40-item PDS were subjected to Exploratory Factor Analysis (SPSS version 19). Consistent with the findings of (Paulhus et al., in press), Exploratory Factor Analysis revealed a 4 factor solution for the SRPIII and a 2 factor solution for the PDS. As highlighted in Table 4, moderate correlations were found between factors for each scale. Some cross-loadings between the IPM and
CA factors were also evident. Finally, items demonstrated significant factor loadings $(>.30)$ and were consistent with those obtained by (Paulhus et al., in press). Therefore, the items and the factor structure of the SRP-III and the PDS were retained in the subsequent statistical analyses.

\section{Scale Reliability}

It is noted that little published research has reported on the internal consistency of both the PDS scales and SRP-III. Therefore, Cronbach's alpha scores were calculated for each of the SRP-III and PDS scales to investigate internal reliabilities and are presented in Table 2. The scores for the PDS demonstrated satisfactory psychometric properties while the SRP-III demonstrated good to excellent psychometric properties (Tabachnick \& Fidell, 2007). Reliability coefficients from the current study are consistent with or elevated com- 
Table 4. Bivariate Correlations for Age, Salary, Drinking Total Score, SRP-III Sub-factors (CA, CT, ELS, IPM), and PDS Scores (SDE \& IM)

\begin{tabular}{|c|c|c|c|c|c|c|c|c|c|c|c|}
\hline & 1. & 2. & 3. & 4. & 5. & 6. & 7. & 8. & 9. & 10. & 11. \\
\hline 3. Drinking Total Score & & & - & $.30 * *$ & $.26 * *$ & $.38 * *$ & $.34 * *$ & $.38^{* *}$ & $-.30 * *$ & -.07 & $-.25 * *$ \\
\hline 4. IPM & & & & - & $.74 *$ & $.65^{* *}$ & $.56^{* *}$ & $.89 * *$ & $-.57 * *$ & -.07 & $-.44 * *$ \\
\hline 6. ELS & & & & & & - & $.51 * *$ & $.85^{* *}$ & $-.50 * *$ & -.13 & $-.43 * *$ \\
\hline 7. CT & & & & & & & - & $.75^{* *}$ & $-.33 * *$ & -.04 & $-.25 * *$ \\
\hline 8. SRP-III & & & & & & & & - & $-.55 * *$ & -.11 & $-.45 * *$ \\
\hline 9. IM Score & & & & & & & & & - & $.20^{* *}$ & $.83 * *$ \\
\hline
\end{tabular}

Note. ${ }^{*} p<.05,{ }^{* *} p<.01$ (two-tailed); IPM = Interpersonal Manipulation. CA = Callous Affect. ELS = Erratic Lifestyle.

$\mathrm{CT}=$ Criminal Tendencies. SRP-III = Self-Reported Psychopathy. IM = Impression Management. SDE = Self-Deceptive Enhancement.

PDS $=$ Paulhus Deception Scales.

pared to Cronbach's alpha scores from the original study sample.

\section{Comparison of Sample Norms}

Means and standard deviations for the SRP-III scales, categorised by gender, are presented in Table $\mathbf{3}$ in comparison to the original scale norms. Table $\mathbf{3}$ also provides means and standard deviations for the general 'norm' population for the PDS subscales and PDS totals (Paulhus, 1998) in comparison to those from the current study, also categorised by gender. In general, SRP-III scores are lower for both males and females in the present study compared to the original 'norm' sample, but the PDS scores are higher. In the present study, on average, males scored higher than females on all four SRP-III subfactors and self-deceptive enhancement, while females had higher impression management and selfdeception scores. Overall there was a wide distribution of SRP-III total scores, ranging from $72-297$, and the mean is considerably lower than incarcerated populations which has been reported at 180.21 (Baskin-Sommers et al., 2011). However, it is noteworthy that fourteen participants' SRP-III total scores were identified to be $2+S D$ 's above the mean $(M$ $=127.46, S D=28.52)$. Four of these participants were identified to be $3+S D$ 's above the mean, which suggests high levels of psychopathic tendencies.

A series of one-way repeated measured ANOVAs were also conducted to compare the means of the SRP-III subfactors. Significant differences were found between all four subfactor means, Wilks' Lambda $=.22, F(3,297)=355.37$, $p<.001$, (multivariate partial eta squared) $\eta^{2}=.78(r=.88)$. Subsequent post hoc multiple comparisons also indicated significant differences between all combinations of the four subfactor means with erratic lifestyle having the highest mean $(M=37.46)$, followed by interpersonal manipulation
$(M=34.48)$ then callous affect $(M=32.88)$ and lastly criminal tendencies $(M=22.65)$.

Regarding overall PDS scores, participants were much more likely to engage in impression management tendencies compared to self-deceptive enhancement e.g., $M=8.36$ vs $M$ $=2.88$. In regards to total PDS scores, a closer inspection revealed that 22 female and 5 male $(n=27)$ participants scored above 70 ("very much above average") and 2 males scored below 30 ("very much below average").

\section{Correlations}

Bivariate correlations (Pearson's $r$ ) were conducted to explore whether there were any relationships between the SRP-III and PDS subfactors, as well as sociodemographic characteristics such as age, salary, drinking total scores, etc. The correlations indicated a number of significant, albeit weak, relationships between the variables. For instance and notably, as age increased, so did impression management scores $(r=.19)$ while drinking scores $(r=-.17)$, IPM $(r=-$ $.27), \mathrm{CA}(r=-.18)$, ELS $(r=-.24), \mathrm{CT}(r=-.12)$ and SRP-III scores $(r=-.25)$ all significantly decreased (all $p$ s two-tailed $<.01)$. On a lesser note, salary was not associated with the SRP-III or PDS factors, however a significant, though very weak positive relationship was revealed between drinking and salary $(r=.13)$. A significant negative relationship between impression management and drinking $(r=-.30, \mathrm{p}<$ .01 ) indicated that the more participants' (mis)used alcohol, the less likely they were to engage in impression management. As expected, the four SRP-III subfactors were highly interrcorrelated, as were the components of the PDS scale: impression management and self-deceptive enhancement. However, in regards to current study's central research question, significant negative relationships were identified between SRP-III subfactor and total scores and PDS scores such that the higher participants' SRP-III score, the lower the 
PDS scores. This was particularly the case with impression management scores, indicating that as psychopathy increased, impression management decreased. Closer scrutiny of the data at an individual level revealed that seven of the participants who scored the highest SRP-III scores also had the lowest impression management scores. Taken together, age, drinking level, impression management and PDS total scores were therefore indicated as having significant, though weak to average relationships with all of the SRP-III subfactor and total scores. In contrast salary and self-deceptive enhancement appeared to have no relationships with the SRPIII subfactors, and thus no further analyses were undertaken.

\section{DISCUSSION}

The study of psychopathy, particular the extent and measurement of psychopathic tendencies, continues to receive increasing research attention. While such research endeavours have traditionally focused on forensic populations, researchers propose there are a number of benefits associated with examining non-incarcerated samples, in particular, studying the construct without the possibly confounding effects of criminality or long-term institutionalisation (Kirkman, 2002). As a result, the current study aimed to examine the existence and prevalence of psychopathic traits within a community sample as well as investigate the relationship between psychopathy and impression management, given the tendency for such individuals to be inclined to use deception.

Firstly, it is noteworthy that similar to the small amount of research in this area (Kirkman, 2002; Neuman \& Hare, 2008 ) approximately $1 \%$ of the sample (e.g., $n=4)$ demonstrated clear psychopathic tendencies. However, because the SRP-III measures psychopathy as a dimensional construct, there is no line drawn between 'psychopathy' and 'nonpsychopathy'. Nevertheless, the current results indicate that there are differing degrees of psychopathy detectable within this community sample, and the current four participants scored remarkably higher on the psychopathy scale than the majority of the sample. In regards to the type of psychopathy and consistent with previous research (DeMatteo et al., 2006), it was expected that a community sample would record significantly higher affective/interpersonal (Factor 1: CA and IPM) scores than behavioural (Factor 2: ELS and $\mathrm{CT}$ ). Results did not support this hypothesis, as the current sample, on average, scored significantly higher in erratic lifestyle followed by interpersonal manipulation, callous affect and lastly by criminal tendencies. This is despite their relatively high functioning capacities within the community, which was reflected in their education and salaries. However this may in fact be expected, given the non-criminal element of the sample.

In regards to those with higher psychopathic tendencies, the results revealed that that those from this community sample who were more likely to have erratic lifestyles, engage in interpersonal manipulation, display callous affect and be inclined towards criminal tendencies were younger males who (mis)used alcohol. In regards to the former, this finding is consistent with the majority of psychopathy research that places young males in the highest scoring psychopathy category (e.g. Forth et al., 1996; Huchzermeier et al., 2008; Lilienfeld \& Hess, 2001, Williams \& Paulhus,
2004; Zagon \& Jackson, 1994). In fact, males in the current study scored considerably higher than females on all SRP-III subfactor and total scores and thus not surprisingly, gender is an important variable in predicting psychopathy scores in this sample. In regards to the later, the results also indicate that those with higher psychopathy scores are more likely to misuse alcohol (or those who misuse alcohol tend to have higher psychopathy scores). This result is notable in light of additional research suggesting that psychopathy and substance abuse are often comorbid (Walsh et al., 2007), or at the very least APD and substance abuse (Hubbard et al., 2996; Westermeyer \& Thuras, 2005). Also unsurprisingly, drinking and erratic lifestyle scores increased together.

In regards to the central aim of the study, individuals who demonstrated the highest psychopathic traits were less likely to utilise impression management. The fact, half of those individuals scoring among the highest SRP-III scores also scored among the lowest impression management scores, which suggests impression management tendencies did not obstruct the identification of psychopathy in this community sample. Additionally and given that erratic lifestyle was the highest scoring SPR-III subfactor, this factor was also inversely related to impression management. This suggests that the more erratic an individual's lifestyle, the less likely they were to utilise impression management. Though erratic lifestyle was not significantly related to self-deceptive enhancement, erratic lifestyle did indicate a negative relationship with overall PDS scores, again suggesting that those reporting erratic lifestyles did not engage in deception. Furthermore, those who scored higher on interpersonal manipulation (which was the second highest SRP-III factor) also scored lower on impression management and on deception subfactor (PDS). That is, an increased propensity for the interpersonal manipulation of other people (presumably in their lives) did not directly translate to manipulation of the assessment process. Additionally, those with higher criminal tendencies scores were less likely to engage in impression management, although this has also previously been found among samples of violent offenders (Mills \& Kroner, 2006). The results have important implications for future research (on larger and more varied community samples) as the issue of deception may not prove to negate the identification of individuals with elevated psychopathic tendencies. This result may further confirm current scientific understanding of the psychopathy construct (as well as re-affirm criteria used within assessment practices) as it is believed that such individuals who demonstrate these traits do not misrepresent the truth in an effective manner (Hare, 1991). It is noteworthy that this issue may prove to extend beyond purely forensic and/or incarcerated populations, and thus may also be relevant for community-based populations.

Taken together, this study has provided preliminary evidence that deception, specifically impression management, does not obstruct the identification of higher functioning individuals with psychopathic traits when identified using self-report methods. While previous research purports the susceptibility of self-report methods to response distortion (Edens et al., 2001), this study is consistent with previous research (Mills \& Kroner, 2003; Mills \& Kroner, 2006) contributing to the debate by suggesting that self-report methods 
may indeed be appropriate for detecting psychopathy, though further research is necessary to generalise these results. The present study also provides support for the utilisation of the SRP-III to identify individuals with psychopathic tendencies within a community sample, given that the distribution of SRP-III scores (in particular $1 \%$ of the sample presenting with clearly elevated scores) is consistent with other preliminary research in the area (Neumann and Hare, 2008).

However, a number of limitations should be borne in mind when interpreting the results. First, the sample was to an extent, one of convenience in that a snowballing effect was utilised which most likely contributed to a significant proportion of the sample being well educated and employed. Second, although an attempt was made by using the PDS to detect those inclined towards deception, the self-report and anonymous nature of the study means that there is no way of verifying the truthfulness of demographic information provided by participants. It is possible that some participants may have felt uncomfortable accurately reporting sensitive information such as criminal history or alcohol/drug use, despite anonymity assurances. Thirdly, individuals with high psychopathy levels may not have had any incentive to misrepresent the truth given there was nothing to gain in the current study. Future research would benefit from assessing the relationship between psychopathy and deception in an experimental environment where the psychopath has an incentive to cheat or misrepresent the truth. Fourthly, there are some variables linked to the psychopathy construct by previous research that were omitted at the design stage of this study e.g., ethnic background, etc. Finally and similar to previous research, there was an uneven gender distribution as the greatest proportion were female e.g., approx $70 \%$.

In regards to future research, the existence and affect of impression management tendencies would be further clarified if the provided self-report data was compared with more objective data (e.g., traffic histories, criminal histories, etc) among larger sample sizes. Furthermore, research may need to consider whether those with psychopathic tendencies are in fact more likely to believe it is desirable to have qualities which others might interpret as unwanted, and therefore not be compelled to present self-reported information about themselves in a more positive light (Levenson et al., 1995). Nevertheless, future research that continues to identify and examine the existence of integrated psychopaths within the community who have not displayed criminal behaviours resulting in prosecution provides an ideal opportunity to disentangle the attributes that characterise psychopathy and criminality.

\section{CONCLUSION}

The current research indicates that impression management tendencies (such as deception) may not negate the identification of individuals with higher psychopathy levels. Additionally, there is some tentative support for the use of the SRP-III to identify individuals with psychopathic tendencies. Finally, younger males who misuse alcohol are more likely to be assessed with higher psychopathy levels in the commu- nity, and thus, further research as well as community based interventions should be directed towards this group.

\section{ACKNOWLEDGEMENTS}

None declared.

\section{CONFLICT OF INTEREST}

The authors confirm that this article content has no conflicts of interest.

\section{REFERENCES}

Baskin-Sommers A., Newman, J., Sathasivam, N., \& Curtin, J. (2011) Evaluating the generalizability of a fear deficit in psychopat+hic African American offenders. Journal of Abnormal Psychology, 120(1), 71-78.

Book, A., Holden, R., Starzyk, K., Wasylkiw, L., \& Edwards, M. (2006). Psychopathic traits and experimentally induced deception in selfreport assessment. Personality and Individual Differences, 41, 601608.

Coid, J., \& Ulrich, S. (2010). Antisocial personality disorder is on a continuum with psychopathy. Comprehensive Psychiatry, 51, 426-433.

Cooke, D.J., \& Michie, C. (2001). Refining the construct of psychopathy: towards a hierarchical model. Psychological Assessment, 13, 171188.

Coid, J., Yang, M., Ullrich, S., Roberts, A., \& Hare, R. (2009). Prevalence and correlates of psychopathic traits in the household population of Great Britain. International Journal of Law and Psychiatry, 32(2), 65-73.

Del Gaizo, A. L., \& Falkenbach, D. M. (2008). Primary and secondary psychopathic-traits and their relationship to perception and experience of emotion. Personality and Individual Differences, 45, 206212.

DeMatteo, D., Heilbrun, K., \& Marczyk, G. (2005). Psychopathy, risk of violence, and protective factors in a noninstitutionalized and noncriminal sample. International Journal of Forensic Mental Health, 4(2), 147-157.

Edens, J.F., Buffington, J.K., Tomicic, T.L., \& Riley, B.D. (2001). Effects of positive impression management on the psychopathic personality inventory. Law and Human Behavior, 25(3), 235-256.

Forth, A. E., Brown, S. L., Hart, S. D., \& Hare, R. D. (1996). The assessment of psychopathy in male and female noncriminals: reliability and validity. Personality and Individual Differences, 20(5), 531543.

Hare, R. D. (1991). The Hare Psychopathy Checklist - Revised. Toronto, Ontario: Multi-Health Systems.

Hare, R., Neumann, C. (2010). The role of antisociality in the psychopathy construct: comment on Skeem and Cooke (2010). Psychological Assessment, 22(2), 446-454.

Huchzermeier, C., Friedemann, G., Kohler, D., Brub, E., Godt, N., Hinrichs, G., \& Aldenhoff, J.B. (2008). Are there age-related effects in antisocial personality disorders and psychopathy? Journal of Forensic and Legal Medicine, 15, 213-218.

Hubarrd, R., Dunteman, G., Craddock, S., Luckey, J., \& Flynn, P. (1996). Comorbidity of antisocial personality and mood disorders among psychoactive substance-dependent treatment clients. Journal of Personality Disorders, 10(1), 56-67.

Kirkman, C.A. (2002). Non-incarcerated psychopaths: why we need to know more about the psychopaths who live amongst us. Journal of Psychiatric and Mental Health Nursing, 9(2), 155-160. Retrieved from http://www.wiley.com/bw /journal.asp?ref=1351-0126\&site= 1

Kropp, P.R., \& Rogers, R. (1993). Understanding malingering: Motivation, method, and detection. In M. Lewis \& C. Saarni (Eds.), Deception and lying in everyday life. New York: Guilford.

Kucharski, L.T., Duncan, S., Egan, S.S., \& Falkenbach, D.M. (2006). Psychopathy and malingering of psychiatric disorder in criminal defendants. Behavioral Science and the Law, 24(5), 633-644.

Levenson, M.R., Kiehl, K.A., \& Fitzpatrick, C.M. (1995). Assessing psychopathic attributes in a noninstitutionalized population. Journal of Personality and Social Psychology, 68(1), 151-158.Retrieved from http://www.apa.org/pubs/journals/psp/ 
Lilienfeld, S.O. (1994). Conceptual problems in the assessment of psychopathy. Clinical Psychology Review, 14(1), 17-38.

Lilienfeld, S. O., \& Hess, T. H. (2001). Psychopathic personality traits and somatization: sex differences and the mediating role of negative emotionality. Journal of Psychopathology and Behavioral Assessment, 23(1), 11-24.

Livesley, W.J., Schroeder, M.L., Jackson, D.N., \& Jang, K.L. (1994). Categorical distinctions in the study of personality disorder: implications for classification. Journal of Abnormal Psychology, 103(1), 617. Retrieved from http://www.apa.org/pubs/journals/abn/

Mahmut, M.K., Homewood, J., \& Stevenson, R.J. (2008). The characteristics of non-criminals with high psychopathy traits: are they similar to criminal psychopaths? Journal of Research in Personality, 42(3), 679-692.

Mealey, L. (1995). The sociobiology of sociopathy: an integrated evolutionary model. Behavioral and Brain Sciences, 18, 523-599.

Mills, J.F., Loza, W., \& Kroner, D.G. (2003). Predictive validity despite social desirability: evidence for the robustness of self-report among offenders. Criminal Behaviour and Mental Health, 13, 140-150.

Mills, J.F. and Kroner, D.G. (2006). Impression management and self-report among violent offenders. Journal of Interpersonal Violence, 21, 178-192.

Neuman, C.S., \& Hare, R.D. (2008). Psychopathic traits in a large community sample: links to violence, alcohol use, and intelligence. Journal of Consulting and Clinical Psychology, 76(5), 893-899.
Paulhus, D.L., (1998). Paulhus deception scales (PDS): The balanced inventory of desirable responding-7: user's manual. Toronto: MultiHealth Systems Inc.

Paulhus, D.L., Hemphill, J.D., \& Hare, R.D. (in press). Manual for the SelfReport Psychopathy scale. Toronto: Multi-Health Systems.

Robins, L. N. (1991). Conduct Disorder. Journal of Child Psychology \& Psychiatry \& Allied Disciplines, 32(1), 193-21.

Ross, S. R., \& Rausch, M. K. (2001). Psychopathic attributes and achievement dispositions in a college sample. Personality and Individual Differences, 30(3), 471-480.

Salekin, R.T., Trobst, K.K., \& Krioukova, M. (2001). Construct validity of psychopathy in a community sample: a nomological net approach. Journal of Personality Disorders, 15(5), 425-441.

Seto, M., Khattar, N., Lalumiere, M., Quinsey, V. (1997). Deception and sexual strategy in psychopathy. Personality and Individual Differences, 22, 301-307.

Westermeyer, J., \& Thuras, P. (2005). Association of antisocial personality disorder and substance disorder morbidity in a clinical sample. American Journal of Drug and Alcohol Abuse, 31(1), 93-110.

Widom, C.S. (1977). A methodology for studying noninstitutionalized psychopaths. Journal of Consulting and Clinical Psychology, 45(4), $674-683$. Retrieved from http://www.apa.org/pubs/journals/ccp/

Williams, K. M., \& Paulhus, D. L. (2004). Factor structure of the SelfReport Psychopathy scale (SRP-II) in non-forensic samples. Personality and Individual Differences, 37(4), 765-778.

Zagon, I. K., \& Jackson, H. J. (1994). Construct validity of a psychopathy measure. Personality and Individual Differences, 17(1), 125-135.

Received: June 18, 2012

Revised: August 09, 2012

Accepted: August 09, 2012

(c) Freeman and Samson; Licensee Bentham Open.

This is an open access article licensed under the terms of the Creative Commons Attribution Non-Commercial License (http://creativecommons.org/licenses/by-nc/3.0/) which permits unrestricted, non-commercial use, distribution and reproduction in any medium, provided the work is properly cited. 